\title{
versants
}

\section{De las geografías a las geopolíticas del hispanismo}

\author{
Gloria Chicote ${ }^{\mathrm{I}}$ \\ Conicet - Universidad Nacional de La Plata - Argentina
}

\begin{abstract}
El presente artículo propone indagar en las configuraciones geopolíticas del hispanismo del siglo XXI, desde una perspectiva plural e integradora que parte de los orígenes decimonónicos de la disciplina para incorporar los debates actuales atravesados por los avatares culturales, sociales y políticos del siglo xx. A lo largo de estas páginas se ofrece una mirada panorámica acerca de la historia y el presente de los hispanismos europeo, americano, asiático y africano, con el propósito de señalar sus respectivas especificidades y establecer puentes que permitan el desarrollo de diálogos futuros.
\end{abstract}

Keywords: Hispanismo, geopolítica, lengua, cultura.

\section{Redefiniciones del hispanismo}

El Diccionario de la Real Academia define el hispanismo como la «afición al estudio de las lenguas, literatura o cultura hispánicas». Acepciones anteriores restringían el atributo de hispanista a extranjeros versados en hispanismo, en consonancia con el campo disciplinario que había nacido en ámbitos no hispanófonos. Quizás por esta razón en el segundo congreso de la Asociación Internacional de Hispanistas celebrado en Nimega en 1967, Dámaso Alonso necesitó puntualizar que el hispanismo hermana a todos los interesados por la cultura hispánica, destacando la incidencia de ingleses, franceses y alemanes, pero también incluyendo a los agentes de la propia cultura, o sea a los españoles y americanos. Más tarde, Frederik Pike (I97I) definió el hispanismo como un movimiento de estudiosos que comparten la misma fe en la existencia de una gran familia, comunidad, o raza hispánica transatlántica, englobando sus múltiples expresiones de ambos lados del océano. Egido (2003) también puntualiza que el hispanismo no tiene fronteras y que se extiende a todo el ámbito de la lengua, la literatura y la cultura en español. En este sentido todos y cada uno de los componentes de ese colectivo estamos en libertad de apropiarnos del concepto y de resignificarlo desde el cronotopo en que estamos ubicados, para decirlo en términos bajtinia-

I Gloria B. Chicote (Facultad de Humanidades y Ciencias de la Educación de la Universidad Nacional de La Plata - Conicet, Argentina), Presidenta de mesa. Con la colaboración de Susan Byrne (Universidad de Nevada, EEUU); Geneviève Fabry (Universidad Católica de Lovaina, Bélgica); Araceli Guillaume-Alonso (Instituto de Estudios Hispánicos, La Sorbona, París, Francia); Zeljko Jovanovic (Serbia, vive y trabaja en Madrid para el CSIC); Vibha Maurya (Departamento de Estudios Germánicos y Romances de la Universidad de Delhi, India); Ahmed Mohamed Mgara (Hispanista, poeta y periodista, Marruecos). 
nos (Bajtin I975), como un conocimiento situado (Haraway I99I), o como un intento de posicionamiento en las formas de alienación y aceleración (Rosa 20I6), regionalidad y globalización, «archipiélagos de la globalización» (Ette \& Müller 20I2), que se constituyen en la sociedad posmoderna.

Más allá de la manifestación de una "fe" cultural compartida, es indudable que la propagación de la lengua castellana, iniciada con las conquistas del reino de Castilla en los siglos XV y XVI, creó la base de la ideología del hispanismo. A partir de entonces se desarrolló un proceso que puede denominarse "hispanización" y que dio como resultado una identidad hispana, un lazo de comunidad entre países y personas que, hasta el presente, usan la misma lengua, a pesar de que, a principios del siglo xIx, el espacio original se fragmentó con la creación de los estados americanos y de que, a partir de entonces, se desencadenaran tensiones teóricas que aún hoy son objeto de acalorados debates.

Estas fragmentaciones que avanzaron de la mano de las políticas nacionales y regionales del estado español y de los diferentes estados americanos fueron construyendo una definición de Hispanismo que lo conecta con un accionar geopolítico en el que se engloban perspectivas históricas, culturales, lingüísticas y literarias.

En el siglo XXI, no podemos negar la existencia de un Hispanismo poligenético que no solo se remonta a sus orígenes decimonónicos sino que estuvo atravesado por los avatares culturales, sociales y políticos del siglo xx.

Julio Ortega (20I0, 20I2) parte de la premisa de que el nuevo hispanismo que hoy interactúa en foros y publicaciones es consecuencia del proceso de renovación de los estudios literarios que empezó poniendo en duda la validez universal del canon consagrado por las distintas tradiciones académicas y la apertura a la validez de la interpretación y los turnos de diálogo. Un nuevo hispanismo plural comenzó a proyectarse más horizontal y dialógico, luego se consolidó desde una nueva geotextualidad desde la perspectiva de la crítica transatlántica, y actualmente asume este rico debate desde una mirada inclusiva considerando todas sus instancias como válidas. Esta conversación resulta intelectualmente innovadora, capaz de articular distintas tradiciones analíticas, institucionales y metodológicas, a la vez que organiza mapas rizomáticos. Los nuevos hispanismos comienzan por cuestionar la retórica de su propia genealogía: preguntan por quién habla, desde qué posicionamiento y para cuál propósito. Por esta razón solo pueden ser plurales e insertos en una concepción de humanismo internacional.

Es necesario asimismo integrar el concepto de diáspora a una mirada geo-referenciada del hispanismo. Las grandes diásporas fueron uno de los estigmas del siglo xx: hombres y mujeres que recorrieron el mundo porque soñaban con un espacio de realización de sus utopías, porque fueron expulsados por el hambre o por razones políticas, porque fueron obligados 
a viajar a espacios de los que nunca regresaron. Todas las diásporas, al decir de Arjun Appadurai (200I), introducen la fuerza de la imaginación, ya sea como memoria o deseo, dando lugar a nuevas mitografías que pasan a convertirse en estatutos fundacionales de nuevos proyectos sociales y no son simplemente un contrapunto de las certezas de la vida cotidiana. El bagaje multiforme de voces que se transmitían a través de la letra impresa da cuenta de estos movimientos físicos y mentales, ya que conjuntamente contribuía a recuperar la memoria de la tierra que los inmigrantes debieron dejar y volvía reiteradamente como una necesidad de reencontrarse con personajes, espacios, hábitos, gustos, que una vez más se resignificaban en nuevas situaciones de vida. El movimiento de personas conllevó el tránsito de múltiples voces que constituyó una fuerza renovada para la lengua y la cultura producidas en español.

Tal como enuncian los distintos informes de los hispanismos nacionales presentados en el encuentro que nos convocó en Madrid en septiembre de 20I8, estamos frente a una definición inestable, incierta e insegura de hispanismo en un interregnum entre nativismos y extranjerías, hispanofilias e hispanofobias que merece ser analizado. El hispanismo del presente está necesariamente alejado de la ideología portadora del primer proyecto geopolítico y del campo de investigación originado en la filología histórico-positivista; ese proceso de nueva reconfiguración quizás explique su ambigüedad conceptual e imprecisión de límites. Por ejemplo: ¿El hispanismo se limita a España o también incluye América Latina? ¿Se centra en la literatura, la historia o la cultura? ¿Es necesario que un hispanista sea también hispanófilo? Y en tal caso, ¿eso implica la afición por España, por Latinoamérica o tan sólo el conocimiento de la lengua? ${ }^{2}$ A lo que podría agregarse, ¿el hispanismo se limita a las culturas en español o incluye también las expresiones literarias y culturales en otras lenguas en contacto como el catalán, el vasco, el gallego, el guaraní, el quechua o el náhuatl, por mencionar solo algunas? Intentaremos profundizar estos interrogantes sin dejar de lado que el estatus actual del hispanismo no solo debe ser pensado hacia el interior de su desarrollo sino también en un contexto de restricción internacional de los espacios humanísticos y "liberales" en un momento de recortes presupuestarios en las instituciones académicas que cuestionan el futuro de las disciplinas humanísticas en su conjunto.

2 Retomo preguntas formuladas por Sebastiaan Faber (2005: 65). 


\section{Perspectivas plurales}

La constitución de esta mesa ${ }^{3}$ con integrantes de Francia, Bélgica, EE.UU., Serbia, India, Marruecos y Argentina, puede servir de ejemplo de la dispersión geográfica (y geo-política) del hispanismo. La conclusión que arrojan los informes es la diferencia del desarrollo del hispanismo en los países centrales (Europa y EE.UU.) en relación con lo acontecido en Asia o África, la dispar incidencia de instituciones públicas o privadas tanto españolas como hispanoamericanas (en menor medida), y el grado de participación de los agentes culturales en redes internacionales tales como la Asociación Internacional de Hispanistas (AIH), la Asociación Hispánica de Literatura Medieval (AHLM), o la Asociación Internacional "Siglo de Oro" (AISO), entre otras.

Tanto los hispanismos francés y belga como el estadounidense dan muestra de un recorrido histórico que conecta los proyectos culturales de los distintos países con los avatares políticos y la relación con asociaciones y sistemas de promoción en el presente.

Araceli Guillaume Alonso realiza una apropiada síntesis del Hispanismo francés desde sus orígenes en el siglo xix, a partir de la presencia de figuras destacadas tales como Alfred Morel-Fatio y Raymond Fouché-Debosc, quien fundó en I894 y dirigió en Paris la célebre Revue Hispanique, primera revista científica dedicada a los estudios hispanistas. En Burdeos, desde I899, se editó el Bulletin Hispanique más orientado a la enseñanza. En este devenir histórico se destaca la idea de reciprocidad entre Francia y España en su afán por un mejor conocimiento mutuo: difundir el español y su cultura en Francia y el francés en España, fue el objetivo de la fundación de l'École des Hautes Études Hispaniques de Madrid (después Casa de Velázquez) de larga trayectoria hasta la actualidad.

Asimismo cabe destacar que desde el siglo xIX el hispanismo francés incluye el hispanoamericanismo en sus vertientes históricas, culturales y lingüísticas. De este hecho da cuenta la creación del IHEAL (Institut des Hautes Études de l'Amérique Latine) y la presencia de las figuras de Ernest Martinenche y Georges Dumas, quienes fueron pioneros en la inclusión de la cultura latinoamericana en la perspectiva hispanística. Esta orientación se vio reforzada durante la Guerra civil española a través de la inserción en las instituciones francesas de intelectuales republicanos, momento clave en el diálogo intercultural en el que cabe destacar el accionar de Marcel Bataillon. Por otra parte la enorme importancia numérica-siempre en auge- de los estudiantes de español son determinantes para entender el hispanismo en Francia.

3 Véase nota I. 
Un recorrido histórico análogo se puede apreciar en el hispanismo estadounidense que Susan Byrne lee desde la perspectiva de la agencia cultural. En esa trayectoria se destaca la temprana fundación por parte de Archer Milton Huntington de The Hispanic Society en Manhattan en 1904 (http://hispanicsociety.org), seguida en 1954 en la ciudad de Nueva York por el Spanish Institute, que en 2003 cambió su nombre para reconocer el patronazgo de la Reina Sofía, y ahora se denomina The Queen Sofía Spanish Institute, conocido también por su sigla QSSI, http:// queensofiaspanishinstitute.org. Entre sus actividades se encuentran: un premio de traducción, becas educativas, eventos culturales, promoción y apoyo a la educación en música, baile y artes españolas, además de programas sobre la historia, la economía, y las letras españolas. Las instituciones mencionadas son un ejemplo particularmente feliz y temprano de acciones culturales, pero también se pueden mencionar otros: en 1983 se fundó como parte de New York University el King Juan Carlos I of Spain Center (KJCC, www.kjcc.org).

Es importante señalar el rol que tuvo la academia norteamericana, sobre todo a partir de las voces de exiliados españoles y latinoamericanos, en primer lugar en la ampliación de los contenidos de los estudios hispanistas hacia las culturas y las literaturas hispanoamericanas y, en segundo lugar, como espacio nodal de desarrollos teóricos y críticos referidos al hispanismo. Los debates sobre poscolonialismo y los estudios transatlánticos se generaron en EE.UU. y a partir de entonces atravesaron la identidad del campo intelectual, de tal manera que hoy debemos incluir ese conjunto de debates en una posible reconfiguración del hispanismo (Trigo 20I2).

Por su parte el hispanismo belga, a pesar de su rol fundamental en la cultura de la edad de oro de la literatura española (jcuántas obras señeras se publicaron y difundieron a partir de los Países Bajos del Sur en los siglos XVI y XVIII), ha conocido una institucionalización más reciente. Su fortalecimiento se ha visto reforzado, entre otras cosas, por el éxito de los programas Erasmus a partir de las últimas décadas del siglo pasado, ya que, según informa Geneviève Fabry, España sigue siendo el destino más solicitado por los estudiantes de intercambio Erasmus.

También se debe incluir en el debate las causas que determinaron la creación o no de asociaciones nacionales de hispanistas y la incidencia de redes regionales, tales como la Asociación de Hispanistas de Benelux, que es una excelente atalaya para estudiar las corrientes del hispanismo no sólo en Bélgica, sino también en los Países Bajos y Luxemburgo.

Si posamos la mirada en Europa del este, podemos constatar que los estudios hispánicos se vieron profundamente fragmentados por la redistribución geopolítica de la posguerra. Željko Jovanović señala que actualmente existen esfuerzos institucionales por desarrollar el estudio de las culturas 
hispánicas: por ejemplo la Universidad de Kragujevac en Serbia organizó en 2018 el Segundo Congreso Internacional de Estudios Hispánicos cuyo objetivo principal es reunir hispanistas de la región, la antigua Yugoslavia, para fomentar el desarrollo del hispanismo en un área lingüística y culturalmente unida. Los hispanistas serbios son miembros de varias asociaciones internacionales de estudios hispánicos tales como AIH, AHLM, AISO. La AIH, en particular, está poniendo todo su empeño en fomentar los estudios hispánicos en Europa del Este con iniciativas como la que llevó a cabo en el último congreso de Münster (Alemania) donde financió, junto con la Fundación Duques de Soria, la participación de varios hispanistas de esta región de Europa.

Para referirnos a los hispanismos de Asia y África, nos detendremos en los ejemplos de India y Marruecos. En ambos países se destaca en primer lugar el accionar del Instituto Cervantes y la difusión del español como lengua extranjera. En este punto un denominador común de los informes presentados es la mención a los índices de estudios de español como lengua extranjera. Entonces volvemos a la pregunta: ¿esto forma parte del hispanismo? Si bien la lengua puede ser un motor para la difusión cultural y parala profundización de los estudios hispánicos, no implica necesariamente este recorrido. La enseñanza del español también puede enmarcarse en objetivos utilitarios y mercantilistas, mientras que la vertiente investigativa en cambio se localiza en las universidades y en las agencias científicas, y se interna en las vías de los desarrollos teóricos, diacrónicos y del pensamiento crítico propio de las humanidades.

El hispanismo indio tiene una inserción institucional incipiente. Vibha Maurya menciona una tradición de más de cincuenta años con una expansión horizontal a lo largo y ancho del país a través de la enseñanza de la lengua española. Se señala la presencia del español en centros como Business Schools, instituciones empresariales y de jurisprudencia. En segundo lugar, se menciona un crecimiento vertical a partir de lo actuado en las Universidades. En esta dimensión no han podido extender y proliferar la enseñanza de lenguas extranjeras de la misma manera como los centros de idiomas. En toda la India hay solo unas diez universidades que tienen cursos avanzados con títulos de licenciatura, maestría y doctorado en filología hispánica o estudios hispánicos. De modo que en la India se constata que el hispanismo, proyectado internacionalmente como la cultura en español en todas sus dimensiones, comienza por ser manifestado con el aprendizaje de la lengua española.

Afortunadamente, la India ya cuenta con un buen número de profesionales conectados de una u otra manera con lo hispánico (los filólogos, historiadores, profesionales de arte y cine relacionados con hispanismo, críticos literarios, traductores, sociólogos), sin embargo, no se ha logrado formar 
una asociación india de hispanistas. Es sabido que algunos hispanistas indios han sido elegidos a la junta directiva de AIH, aun así no han podido reunirse en una asociación. Sin embargo, se debe reconocer que los hispanistas en sus propias unidades en distintas universidades son muy activos tanto en el campo de la investigación y producción académica de publicaciones como en la organización de congresos temáticos y generales. Varios de nuestros hispanistas son miembros de la Asociación Internacional de Cervantistas, así como cada dos años se organiza el Congreso Ibero-Asiático de Hispanistas en la Universidad de Delhi. Así que se puede decir con toda seguridad que los hispanistas indios están en constante diálogo con el hispanismo internacional. Asimismo, cabe destacar la importancia de los programas de traducción del español al indi y viceversa, los cuales, financiados fundamentalmente por España, han dado la posibilidad de profundizar el intercambio de lenguas, sociedades y culturas.

Paralelamente, Ahmed Mgara señala que el hispanismo marroquí está atravesando una situación alarmante por haber decaído el número de alumnos de español como segunda lengua en los institutos de enseñanza secundaria, lo que indujo al cierre de muchas aulas y al cercenamiento de las vías de formación de profesores por haber una excedencia en paro de los que ejercían y que no tienen aulas. A nivel universitario sucede algo muy similar. Los últimos cinco años conocieron un retroceso en número de alumnado e incluso en el número de profesores de español. Por último, se señala que en Marruecos los estudios hispánicos se desarrollan sobre la base de emprendimientos en la mayoría de los casos de índole individual.

\section{¿Hispanismo es lengua, literatura y cultura?}

Un punto reiterado en las distintas discusiones es la centralidad de la disciplina literatura en los estudios hispánicos en sus diversas variantes geográficas y lingüísticas. Mientras que en los países hispanohablantes el hispanismo se ocupa preferentemente del estudio de la literatura española, en el resto del mundo ha adquirido cada vez más preponderancia el estudio de la literatura hispanoamericana. A su vez, los estudios de lingüística tienen por su parte otros canales disciplinarios específicos que no se denominan hispanistas y se nuclean en redes y asociaciones de consolidado prestigio internacional.

Hay razones históricas y teóricas que explican parcialmente estas divisiones. Todas las naciones americanas tienen un origen de filiación y diferenciación con la cultura española. Desde distintas posiciones teórico-críticas, términos como "hispanismo", "hispanidad", "panhispanismo", "hispanoamericanismo" acarrearon connotaciones negativas, concebidos, en muchos casos, como formas de supremacía de todo lo que provenía de 
España. Para muchos pensadores americanos la historia del hispanismo no está exenta de la historia del colonialismo español, la ideología de la pureza de la lengua aparejada a la desvalorización de las lenguas autóctonas y de las variedades híbridas emergentes de los procesos de transculturación. Por esta razón, tempranamente se alzaron voces en contra del mote de hispanidad por connotar la necesidad de una unión inquebrantable que desestima la posibilidad de construir sociedades con una dinámica sociocultural propia, portadoras de redes de comunicación y movilidad en espacios descentrados.

En este entramado de discursos, el hispanismo de América, y de Argentina en particular, se caracteriza por un intento de restricción en el alcance del término que es una consecuencia de la tensión fundante antes referida. Mientras que en los hispanismos desarrollados en países en los que el español se estudia como lengua extranjera asistimos a posiciones abarcadoras de la categoría, que incluyen el estudio de la lengua, las literaturas y las culturas española e hispanoamericana, en Argentina como en otros países hispanoamericanos, el término hispanismo nombra la presencia de lo español en la cultura americana y el estudio de la lengua, literatura y cultura españolas. Demás está decir que desde esta perspectiva se excluyen del objeto de estudio del hispanismo las obras literarias americanas pertenecientes a las diferentes literaturas nacionales, tales como la Literatura Mexicana, Colombiana, Peruana, Argentina, etc., reunidas todas ellas bajo el rótulo de Literatura Hispanoamericana, o la denominación más inclusiva de Literatura Latinoamericana, que se extendió últimamente en un esfuerzo por sumar al ámbito lusófono brasileño (Chicote 2003, 2013).

Tal como se ha señalado, este debate carece de sentido en los distintos hispanismos nacionales de los países no hispanohablantes. Un recorrido por los títulos de las tesis de maestrías y doctorales referidas a las disciplinas ejemplifica la importancia de la literatura hispanoamericana en las investigaciones y también el crecimiento de protagonismo de las artes visuales.

La destacada originalidad del hispanismo indio en el campo de investigación y publicación acaso sea la asombrosa pluridisciplinaridad de los proyectos de estudio e investigación tanto individuales como colectivos, que emergen gracias al enfoque en los estudios superiores del nuevo campo de interdisciplinaridad. Este tipo de relaciones ha sido el eje de convocatorias muy importantes de la Unión Europea en los últimos años, en las que se focaliza no solo la comparación de similitudes y diferencia sino el establecimiento de diálogos entre sur / sur en los que vuelven a adquirir centralidad las culturas americanas. 


\section{Caminos posibles de la internacionalización}

Por último vale mencionar el rol fundamental que los foros internacionales han tenido y siguen teniendo en la constitución del Hispanismo, desde la Hispanic Society of America hasta la AIH, AISO, AHLM o Asociación de Cervantistas. Los foros internacionales se constituyen como espacios de diálogo plural y horizontal en los que los investigadores de diferentes países pueden poner en discusión sus realidades diferenciadas y operan asimismo como espacios de construcción de consensos.

También tienen funciones destacadas las instituciones nacionales en relación con la difusión cultural. En este sentido volvemos sobre la cuestión geopolítica ya que tanto España como los países centrales invierten mucho más dinero y esfuerzo en la promoción de la lengua y la cultura propias que los países periféricos. En América, quizás el país que más se ocupó de los procesos de internacionalización fue México y en menor medida Argentina, pero los demás países tienen prácticamente nulos programas. $\mathrm{Al}$ respecto, consideramos una iniciativa auspiciosa la creación de cátedras abiertas y lectorados propiciados por las diferentes embajadas.

Debemos ser conscientes de que si pretendemos elevar una voz compartida de todos los que nos dedicamos al hispanismo, esta voz debe estar de la mano de políticas públicas que la avalen y no de meros desarrollos individuales del ámbito académico.

El desafío actual es constituir un nuevo hispanismo que privilegie los lazos culturales y lingüísticos de forma plural y horizontal, sin estrangular las especificidades y diferencias constitutivas. Las redes culturales, institucionales, académicas están tendidas: debemos nutrirlas con los debates actuales que se multiplican de este y del otro lado del Océano. Propósitos ambiciosos, sin duda, cuya intención primordial es restablecer, debidamente renovado, un campo de estudios literarios y culturales hispánicos profundamente inclusivo y diverso.

\section{Bibliografía}

Alonso, Dámaso, «Perspectivas del hispanismo actual», en Actas del II Congreso de la Asociación Internacional de Hispanistas, eds. Jaime Sánchez Romeralo \& Norbert Poulussen, Nijmegen, Janssen Brothers, 1967, pp. 17-23.

Appadurai, Arjun, La modernidad desbordada. Dimensiones culturales de la globalización, Buenos Aires, Fondo de Cultura Económica, 200I.

Bajtin, Mijail, Teoría y estética de la novela, Madrid, Taurus, 1989.

Chicote, Gloria, «El Hispanismo en Argentina», Boletín de la Fundación Federico García Lorca, 33-34, 2003, pp. 133-39. 
—. «Cuatro postales del Hispanismo Argentino», Ínsula, 793-794, 2013, pp. 34-37.

Egido, Aurora, «Mapa del Hispanismo», Boletín de la Fundación Federico García Lorca, 33-34, 2003, pp. 15-37.

Ette, Ottmar \& Gesine Müller (eds.), Archipels de la mondialisation = Archipiélagos de la globalización: Contribuciones en español, francés, inglés y alemán, Madrid / Fráncfort del Meno, Iberoamericana / Vervuert, 2012.

Faber, Sebastiaan. "La hora ha llegado". Hispanism, Pan-Americanism, and the Hope of Spanish/American Glory (1938 -1948)», en Ideologies of Hispanism, ed. Mabel Moraña, Nashville, Vanderbilt University Press, 2005.

Haraway, Donna, Ciencia, cyborgs y mujeres: la reinvención de la naturaleza, Valencia, Universidad, I99I.

Ortega, Julio (ed.), Nuevos hispanismos interdisciplinarios y transatlánticos, Madrid/ Frankfurt, Iberoamericana/Vervuert, 2010.

- Nuevos hispanismos. Para una crítica del lenguaje dominante, Madrid/Fráncfort del Meno, Iberoamericana / Vervuert, 2012.

Pike, Fredrik, Hispanismo, I898-1936, Notre Dame-London, University of Notre Dame Press, 197I.

Rosa, Harmut, Alienación y aceleración. Hacia una teoría crítica de la temporalidad en la modernidad tardía, Buenos Aires, Katz, 2016.

Trigo, Abril, «Los estudios transatlánticos y la geopolítica del neo-hispanismo», Cuadernos de literatura, 3I, enero-junio 20I2, pp. I6-45. 